\title{
Die effek van die skermgas-samestelling in 'n induktiefgekoppelde plasma: 'n Eindige-elementanalise
}

\begin{abstract}
Outeurs:
NJM Grobler

H Bissett

GJ Puts ${ }^{a}$

PL Crouse ${ }^{a}$

Affiliasies:

aDepartement Chemiese Ingenieurswese, Universiteit van Pretoria, Privaatsak X20, Hatfield 0028, Suid-Afrika. ${ }^{b}$ Afdeling Toegepaste Chemie, Suid-Afrikaanse Kernenergiekorporasie, R104 Pelindaba, Madibeng 0240, Suid-Afrika
\end{abstract}

Korresponderende outeur: NJM Grobler

E-pos:

njmgrobler@gmail.com

Datums:

Ontvang: $\quad 17 / 07 / 20$

Aanvaar: $\quad 26 / 10 / 20$

Gepubliseer: 11/11/20

Hoe om hierdie artikel aan te haal:

NJM Grobler, H Bissett,

GJ Puts, PL Crouse, Die

effek van die skermgassamestelling in ' $n$ induktiefgekoppelde plasma:' $n$ Eindige-elementanalise, Suid-Afrikaanse Tydskrif vir Natuurwetenskap en Tegnologie 39(1) (2020). https://doi.org/10.36303/ SATNT.2020.39.1.799

Kopiereg:

(C) 2020. Authors.

Licensee: Die Suid-

Afrikaanse Akademie vir

Wetenskap en Kuns.

Hierdie werk is onder

die Creative Commons

Attribution License

gelisensieer.
Die skermgas speel 'n belangrike rol in die termiese beskerming van die reaktorwand in 'n induktiefgekoppelde plasmareaktor (IGP). Waterstof ioniseer moeiliker as argon. Waterstof word dus in klein hoeveelhede in die skermgas gebruik waar argon die hoof-plasmagas is om plasmavorming in die omgewing van die wand te verhoed. Die hoë vloeisnelheid van die skermgas verminder ook die tyd vir hitte-oordrag na die wand. Daar is verskeie numeriese modelle van IGP-sisteme in die literatuur; nie een neem die effek van die skermgassamestelling in ag nie. Die hoeveelheid waterstof in die skermgas en sy hoër ionisasiepotensiaal kan groot newe-effekte op die plasmagedrag hê. 'n Oormaat waterstof in die skermgas is ook ' $n$ vermorsing. Beide faktore het ' $n$ invloed op die ekonomie van die plasmaproses. Hierdie navorsing wys dat meer as $2 \% \mathrm{H}_{2}$ in die skermgas benodig word om plasmavorming teen die wand te voorkom. 'n Lokale minimum in stralingsverliese dui daarop dat die optimale skermgassamestelling vir hierdie sisteem $3 \% \mathrm{H}_{2}$ in die argonskermgas is. Die kommersiële eindige-elementgebaseerde sagtewarepakket COMSOL Multiphysics is vir hierdie werk gebruik.

Sleutelwoorde: eindige-elementanalise; induktiefgekoppelde plasma; skermgas.

The efect of sheat-gas composition in an inductively-coupled plasma reactor: A finiteelement analysis: Sheath gas has a crital role in the thermal protection of the inner reactor wall of an inductively-coupled plasma reactor (ICP). Argon ionises more readily than hydrogen. Hydrogen is thus used in small concentrations in the sheath gas when argon is the main plasma gas in order to prevent plama formation in close proximity to the reactor wall. The high linear velocity of the sheath gas further minimises temperature increase of the sheath gas, and thus heat transfer to the reactor wall. Many numerical models of ICPs have been published in the literature; not one has specifically taken the effect of sheath gas into account. The concentration of hydrogen may have deleterious effects on general plasma behaviour, because of its higher ionisation potential. In addition, an excess of hydrogen is costly. Both factors have an influence on the economics of any plasma process. The research reported here shows that more than $2 \% \mathrm{H}_{2}$ in the sheath gas is required to prevent plasma formation at the wall surface. A local minimimum in modelled radiative heat losses indicates the optimal hydrogen concentration to be $3 \%$. The commercial software package COMSOL Multiphysics was used for this work.

Key words: finite element analysis; inductively-coupled plasma; sheath gas.

\section{Inleiding}

Induktiefgekoppelde plasmareaktore (IGP's) het verskeie industriële toepassings, onder andere die voorbereiding van metaalpoeiers vir additiewe vervaardiging (Murr et al., 2012). Sekere metaalprodukte word vervaardig deur middel van persing en sintering van metaalpoeiers. Hierdie tegniek staan as poeiermetallurgie bekend. Metaalpoeiers wat vervaardig word deur middel van piro- en hidrometallurgiese prosesse toon onreëlmatige morfologieë. Hierdie onreëlmatighede bemoeilik die verwerking van die poeiers omdat dit die persingsdruk en sinteringstemperatuur tot bo die teoretiese waardes verhoog. Daarteenoor toon gesferoïdiseerde metaalpartikels ' $n$ homogene morfologie wat toelaat dat die finale produk by baie laer temperature en drukke gesinter kan word. In sekere gevalle is die materiaaleienskappe na prosessering baie naby aan die teoretiese waardes. Derhalwe is gesferoïdiseerde metaalpartikels die gewenste uitgangstof vir poeiermetallurgie. 
Die Suid-Afrikaanse Kernenergiekorporasie (Necsa) het 'n program gevestig vir die bevordering van sferoïdiseringstegnologie met die einddoel om 'n kommersiële, IGPgebaseerde metaalprosesseringsaanleg te bou. Die navorsing wat ons hier rapporteer, fokus op die verstaan en verbetering van titaansferoïdisering. Toetse word tans uitgevoer op 'n Tekna TEKSPHERO-15 kleinskaalse sferoïdiseringsisteem met argon as die hoof-plasmagas (Tekna, 2016).

IGP-sisteme toon groot termiese verliese wat die energieeffektiwiteit van die sferoïdiseringsproses drasties verminder, in hierdie geval aan straling en na die verkoelingswater in die reaktorwand. Dit is noodsaaklik om hierdie energieverliese te verminder om 'n suksesvolle kommersiële aanleg te bou.

Die energie wat deur die wand van die reaktor verloor word, kan verminder word deur die hittesone weg van die wand af te beweeg. Dit kan gedoen word deur 'n skermgas te gebruik wat moeiliker ioniseer as die hoof-plasmagas. Waterstof ioniseer moeiliker as argon en sal dus die hittesone van die wand af wegskuif indien dit teenwoordig in die skermgas is. 'n Oormaat waterstof toon egter neweeffekte op die termiese- en vloeigedrag van die plasma, kan die plasma blus, en onnodig materiaal verkwis.

Die besondere hoë temperature wat in 'n IGP bereik word, maak dit moeilik om eenvoudige lesings soos vloei en temperatuur te neem. Rekenaarmodelle bied dus die geleentheid om die fisiese en chemiese eienskappe van 'n plasma te ondersoek en die gedrag daarvan te analiseer. Die rekenaarmodelle moet egter eksperimenteel bevestig word vir behoorlike interpretasie van die resultate.

Verskeie bestaande IGP-rekenaarmodelle is beskikbaar in die literatuur. Boulos (1978) was van die eerstes om 'n rekenaarmodel vir 'n IGP te ontwikkel. Verskeie aanvanklike modelle het gevolg wat die temperatuur- en vloeivelde bereken (Proulx et al., 1983; Mostaghimi et al., 1985; Yang et al., 1989). Moderne sagtewarepakette gebruik eindige-element/volume-analise wat met ingeboude funksies vir energie- en vloeiberekeninge beskibaar gestel word Voorbeelde van sulke sagteware is COMSOL Multiphysics (2018) en ANSYS Fluent (2018). Ikhlef et al. (2012) het 'n eindige-element COMSOL model vir ' $n$ argon-IGP by atmosferiese druk ontwikkel om sodoende die magnetohidrodinamiese koppelingsgedrag beter te verstaan. Daar is etlike moderne modelle wat die eindige-element/ volume-metode gebruik om verskillende geometrieë van-, of gebruike vir IGP's te simuleer (Bolot et al., 2007; Bogaerts \& Aghaei, 2017; Colombo et al., 2008). Die outeurs is nie bewus van enige bestaande model wat die effek van die skermgas se samestelling in ag neem nie.

Hierdie navorsing poog om die optimale skermgas-samestelling te vind wat hitteverlies deur die plasmareaktor se wand minimeer. Die modellering en simulasies is met
COMSOL Multiphysics gedoen, en het die pakket se ingeboude fisikamodules gebruik. Geen aanvullende kode is geprogrammeer nie en geen eksperimentele resultate word vermeld nie.

\section{Berekeningsmodel Samestellende vergelykings}

COMSOL gebruik 'n wiskundige model ontwikkel deur Boulos et al. (1994) vir die beskrywing van 'n IGP soos hieronder beskryf. Turbulente vloei word aanvaar, die saampersbare vloei in die sisteem word beskryf deur die kontinuïteitsvergelyking, die momentumvergelyking en die $k$ - $\omega$ turbulensievergelykings weergegee in Vergelyking (1) tot (6), met $\omega$ as die spesifieke dissipasietempo.

$$
\begin{aligned}
& \begin{aligned}
& \nabla \cdot(\rho \boldsymbol{u})=0 \\
& \rho(\boldsymbol{u} \cdot \nabla) \boldsymbol{u}=\nabla \cdot\left[-p \mathbf{I}+\left(\mu+\mu_{T}\right)\left(\nabla \boldsymbol{u}+(\nabla \boldsymbol{u})^{T}\right)-\frac{2}{3}\left(\mu+\mu_{T}\right)(\nabla \cdot \boldsymbol{u}) \mathbf{I}-\frac{2}{3} \rho k \boldsymbol{l}\right] \\
&+\boldsymbol{F}
\end{aligned}
\end{aligned}
$$

Vergelyking (1) is die kontinuïteitsvergelyking en Vergelyking (2) is die momentumbalans. Vergelyking (3) tot Vergelyking (6) is die $k$ - $\omega$ vergelykings vir turbulente vloei.

$$
\begin{aligned}
& \rho(\boldsymbol{u} \cdot \nabla) \mathrm{k}=\nabla \cdot\left[\left(\mu+\mu_{T} \sigma_{k}^{*}\right) \nabla \mathrm{k}\right]+P_{k}-\beta_{0}^{*} \rho \omega k \\
& \rho(\boldsymbol{u} \cdot \nabla) \omega=\nabla \cdot\left[\left(\mu+\mu_{T} \sigma_{\omega}\right) \nabla \omega\right]+\alpha \frac{\omega}{k} P_{k}-\beta_{0} \rho \omega^{2} \\
& \mu_{T}=\rho \frac{k}{\omega} \\
& P_{k}=\mu_{T}\left[\nabla \boldsymbol{u}:\left(\nabla \boldsymbol{u}+(\nabla \boldsymbol{u})^{T}\right)-\frac{2}{3}(\nabla \cdot \boldsymbol{u})^{2}\right]-\frac{2}{3} \rho k \nabla \cdot \boldsymbol{u}
\end{aligned}
$$

Hier verteenwoordig $\rho, u, F, T$, $\mu$, en $p$ die digtheid, snelheidsveld, die liggaamskragvektor wat die verskillende kragte op die volume in ag neem, temperatuur, viskositeit, en druk, onderskeidelik.

Die totale hitte-oordrag word deur Vergelyking (7) beskryf en die konduktiewe hittevloed word deur Vergelyking (8) beskryf.

$$
\begin{aligned}
& \rho C_{p} \frac{\partial T}{\partial t}+\rho C_{p} \boldsymbol{u} \cdot \nabla T+\nabla \cdot \boldsymbol{q}=Q+Q_{p}+Q_{v d} \\
& \boldsymbol{q}=-k \nabla T
\end{aligned}
$$

Hier verteenwoordig $Q, Q_{p^{\prime}} Q_{v d^{\prime}} \boldsymbol{q}, C_{p^{\prime}}$ en $k$ onderskeidelik die plasmahittebron, die drukarbeid, die viskose energieverliese, die konduktiewe hittevloed, die spesifieke warmtekapasiteit, en die termiese geleidingsvermoë. Die Maxwell-vergelykings word weergegee in Vergelyking (9) tot Vergelyking (12).

$$
\begin{aligned}
& \nabla \times \boldsymbol{H}=\boldsymbol{J} \\
& \boldsymbol{B}=\nabla \times \boldsymbol{A}
\end{aligned}
$$




$$
\begin{aligned}
& \boldsymbol{J}=\sigma \boldsymbol{E}+j \omega \boldsymbol{D}+\sigma \boldsymbol{v} \times \boldsymbol{B}+\boldsymbol{J}_{\boldsymbol{e}} \\
& \boldsymbol{E}=-j \omega \boldsymbol{A}
\end{aligned}
$$

Hier verteenwoordig $\boldsymbol{H}, \boldsymbol{J}, \boldsymbol{B}, \boldsymbol{A}, \boldsymbol{E}, \omega, \boldsymbol{D}, J_{\boldsymbol{e}^{\prime}} \sigma$, en $\boldsymbol{v}$ onderskeidelik die magneetveldintensiteit, stroomdigtheid, magnetiesevloeddigtheid, magnetiesevektorpotensiaal, elektriese veldintensiteit, frekwensie, die diëlektriese verplasingvektor, ekstern-gegenereerde stroomdigtheid, elektriese geleidingsvermoë, en versnelling van die geometrie relatief tot' $n$ verwysingsgeometrie.

Die plasma-hittebron, $Q$, in Vergelyking (7), word gedefinieer deur Vergelyking (13).

$$
Q=\frac{\partial}{\partial T}\left(\frac{5 k_{B} T}{2 q}\right)(\nabla T \cdot \boldsymbol{J})+(\boldsymbol{E} \cdot \boldsymbol{J})+Q_{\mathrm{rad}}
$$

Hier verteenwoordig $k_{B^{\prime}} q$, en $Q_{\text {rad }}$ onderskeidelik die Boltzman-konstante, die eenheidslading, en die totale volumetriese stralingsverliese. Die eerste term aan die regterkant verteenwoordig entalpie-transport. Die tweede term beskryf Joule-verhitting.

\section{Oplossingsmetodiek}

Die wiskundige model, beskryf deur Vergelyking (1) tot (13), is gebruik om die Tekna plasmareaktor te simuleer. Die model maak gebruik van drie fisikanodes binne COMSOL, nl. vloeidinamika, hitte-oordrag en elektromagnetisme. Die magneetveldnode los die Maxwellvergelykings op vir die elektromagentiese velde opgewek deur die wisselstroom in die klos assook in die plasma. Die COMSOL-plasmapakket koppel die magneetveldnode en die hitte-oordragnode deur die verskaffing van 'n plasmahittebron. Turbulente vloei is aangeneem.

'n Tegniese diagram van die Tekna-reaktor word in Figuur 1 getoon en die vereenvoudiging daarvan vir modelleringsdoeleindes in Figuur 2. Die geometrie in Figuur 2 is ' $n$ praktiese vereenvoudiging van die tegniese diagram. Die

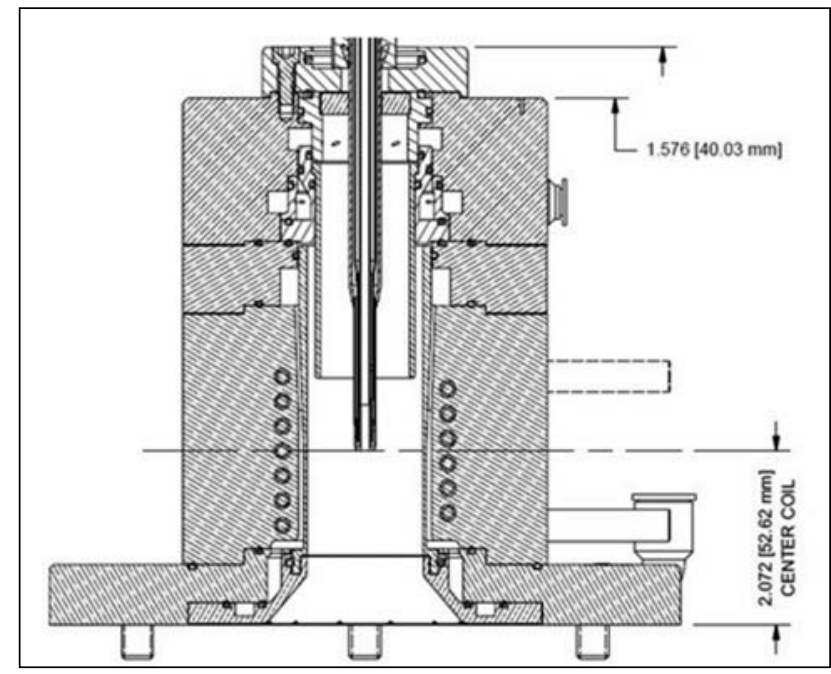

FIGUUR 1: Tegniese diagram van 'n Tekna TEKSPHERO-15 induktiefgekoppelde RF plasmabrander. silindriese simmetrie van die reaktor is vereenvoudig na 'n 2D-aksiaalsimmetriese simulasie, vir 'n drastiese vermindering in berekeningshulpbronne en simulasietyd.

Domein 1 (in Figuur 2) verteenwoordig die wand van die draergassonde en Q1 verteenwoordig die draergasinlaat. Q2 is die hoof-plasmagasinlaat vir suiwer argon, waar Q3 die argon skermgas verteenwoordig wat'n klein varïerende hoeveelheid waterstof bevat. Domein 2 verteenwoordig die sentrale plasmagas. Domein 3 die kwartsbuis wat die plasmagas en skermgas skei. Domein 4 verteenwoordig die skermgas en Domein 5 die wand van die plasmabrander. Die vloeidinamikavergelykings is slegs vir Domein 2 en 4 opgelos, met 'n geenglip-randvoorwaarde vir die wand (grens tussen Domein 4 en 5).

Die grens tussen Domein 2 en 4 is kunsmatig, word slegs vir numeriese doeleindes gebruik, en het geen fisiese effek op die vloei en hitte-oordrag nie. Die grootste beperking van COMSOL is dat dit nie die vermenging van gasse in 'n plasma in ag kan neem nie. Dit lewer die grootste bydrae tot die fout. Die modellering van ' $n$ sisteem met waterstof in die skermgas vereis ' $n$ kunsmatige skeiding tussen twee domeine met verskillende samestellings, wat steeds vir vloei- en hitte-oordrag toelaat. Domein 4 is daarom 'n homogene mengsel van waterstof en argon en die eienskappe hiervoor is addisioneel ingeprogrammeer.

Die hitte-oordrag is bepaal in Domeine 2, 4, en 5. Die hitteoordrag in die res van die geometrie is nie van belang nie aangesien die hitteverlies na die verkoelingswater in die model ingesluit is deur ' $n$ vaste temperatuur van $300 \mathrm{~K}$ op die buitewand te spesifiseer. Die aanvangstemperatuur is op $300 \mathrm{~K}$ gestel vir die volledige geometrie en die aanvanklike vloeiveld op $0 \mathrm{~m} / \mathrm{s}$ is gestel.

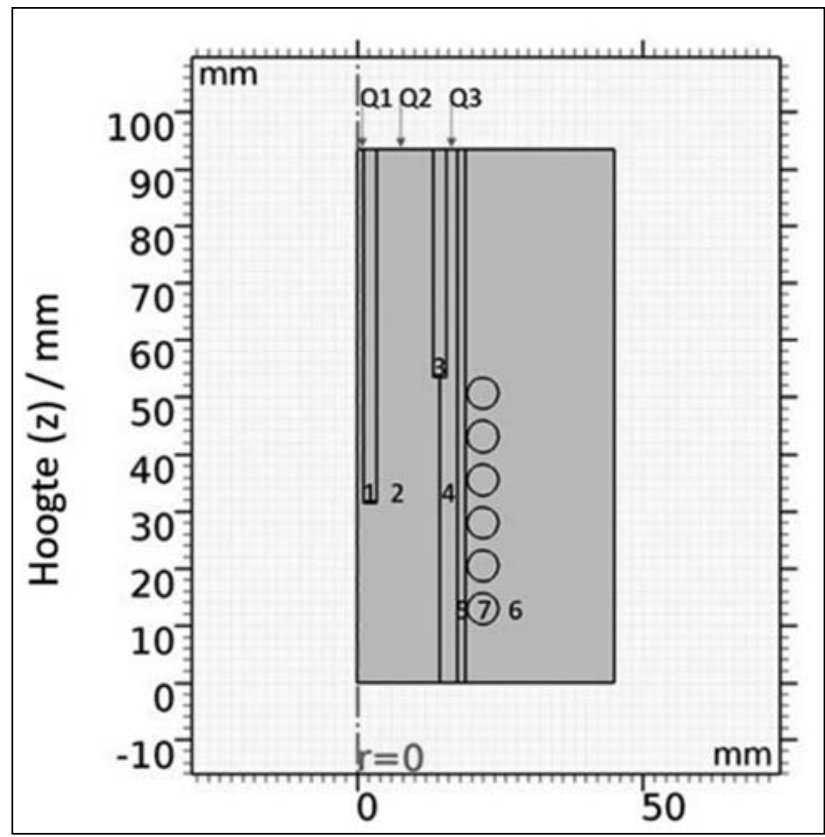

FIGUUR 2: Simulasiegeometrie wat die verkillende domeine en inlate aandui. 
Die sisteem is ondersoek in ' $n$ frekwensie-tyd-domein vir ' $n$ bedryfsperiode van $8 \mathrm{~s}$ aangesien gestadigde toestande na $4 \mathrm{~s}$ bereik word. Verskeie simulasies met verskillende hoeveelhede $\mathrm{H}_{2}$ in die skermgas is gedoen. Tabel 1 bevat die bedryfstoestande en beginwaardes wat konstant gehou is vir al die simulasies.

TABEL 1: Bedryfstoestande en beginwaardes

\begin{tabular}{l|c|c}
\hline Parameter & Waarde & Eenheid \\
\hline Drywing & 11 & $\mathrm{~kW}$ \\
Frekwensie & 3 & $\mathrm{MHz}$ \\
Inlaat 1 (Q1) & 2 & $\mathrm{slpm}$ \\
Inlaat 2 (Q2) & 10 & $\mathrm{~s} / \mathrm{pm}$ \\
Inlaat 3 (Q3) & $40+x$ & $\mathrm{~s} / \mathrm{pm}$ \\
Begin temperatuur & 300 & $\mathrm{~K}$ \\
Aanvanklike vloeiveld & 0 & $\mathrm{~m} / \mathrm{s}$ \\
Aanvanklike magnetiese vektor potensiaal & 0 & $\mathrm{~Wb} / \mathrm{m}$ \\
\hline
\end{tabular}

Die maas is 'n kritiek-belangrike aspek van die simulasieproses. Indien die maas nie fyn genoeg is nie, kan dit 'n diskontinuïteit in die resultate veroorsaak. Die maasstudie is dus gedoen om te bevestig dat die maas fyn genoeg is deur sistematies verskillende groottes te toets. Die punt waar verfyning nie verdere verandering tot gevolg het nie, word as akkuraat genoeg beskou. In baie gevalle kan die maas ook te fyn wees en, behalwe om onnodige rekenaarhardeware te vereis, ook divergente gedrag in die oplossing veroorsaak.

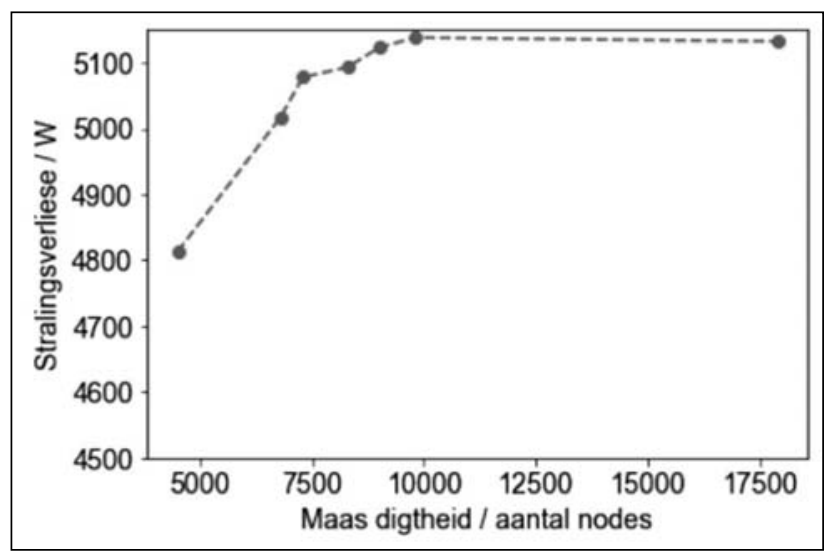

FIGUUR 3: Stralingsverliese van die plasma as 'n funksie van maasdigtheid

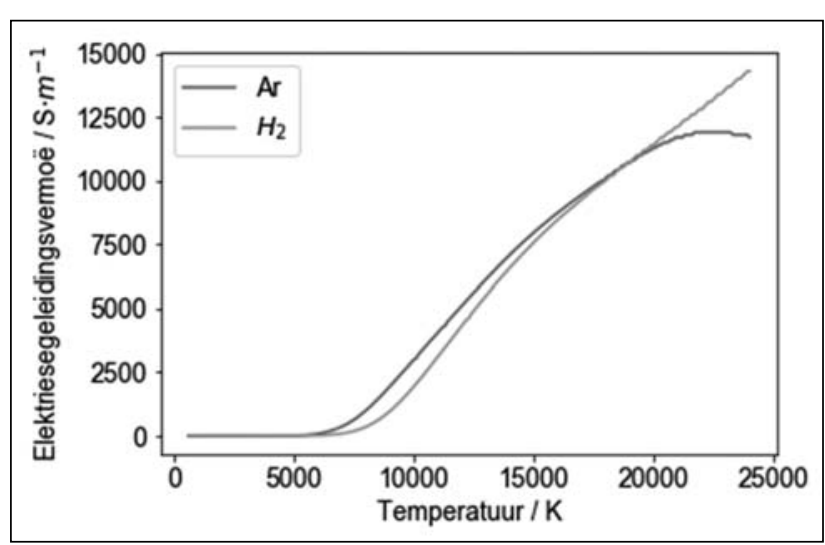

FIGUUR 4: Elektriesegeleidingsvermoë van argon en waterstof as 'n funksie van temperatuur (Boulos et al.,1994).
Sewe verskillende maasdigthede is getoets. Figuur 19 wys hoe die stralingsverliese as funksie van die maasdigtheid verander. Dit is duidelik dat dit rondom 9000 maasnodes stabiliseer. Dit impliseer dat ' $n$ maas van ten minste 9000 nodes benodig word vir 'n akkurate oplossing. Die grofste maas wat getoets is, het 4500 nodes bevat; minder as dit het divergente gedrag in die model veroorsaak.

\section{Resultate en bespreking}

Die hoof-resultate word in Figuur 5 tot Figuur 10 aangetoon. Figuur 6 wys die temperatuur as funksie van afstand vanaf die reaktorwand. Figuur 7 wys die temperatuur $1 \mathrm{~mm}$ van die binnewand as funksie van die konsentrasie $\mathrm{H}_{2}$ in die skermgas. Figuur 7 dui die verandering in totale hittevloed by verskillende $\mathrm{H}_{2}$ konsentrasies. Figuur 9 gee die stralingverliese as funksie van $\mathrm{H}_{2}$ konsentrasie in die skermgas. Figuur 10 wys die radiale temperatuurprofiel by die maksimum temperatuur vir elke simulasie.

Figuur 4 gee die elektriese geleidingsvermoë van waterstof en argon as 'n funksie van temperatuur, soos gebruik deur COMSOL. In die temperatuurgebied van belang, nl., $5000 \mathrm{~K}$ to $\sim 20000 \mathrm{~K}$, is die elektriesegeleidingsvermoë van argon hoër as waterstof. Argon ioniseer meer geredelik as $\mathrm{H}_{2}$. Dit gebeur omdat waterstof van die beskikbare energie gebruik om chemiese bindings te breek.

Figuur 5 toon die tydsverloop van die temperatuur by 'n vaste punt in die middel van die wand op die hoogte waar die maksimum temperatuur bereik word Die temperatuur in die wand lyk of dit 'n gestadigde toestand bereik na $4 \mathrm{~s}$ (Figuur 5). Die simulasies is dus almal vir $8 \mathrm{~s}$ geloop.

Die teenwoordigheid van waterstof beweeg die hittesone na links en verminder plasmavorming by die wand (soos later aangetoon); maar, dit verbeter ook die hitte-oordrag na die wand. Dit word verwag aangesien waterstof 'n beter hittegeleidingsvermoë het as argon. Die verbeterde hittegeleiding na die wand en die groter afstand tussen die wand en die hittesone is twee kompeterende effekte wat lei tot ' $n$ optimale punt waar daar minimale hitte deur die wand verloor word.

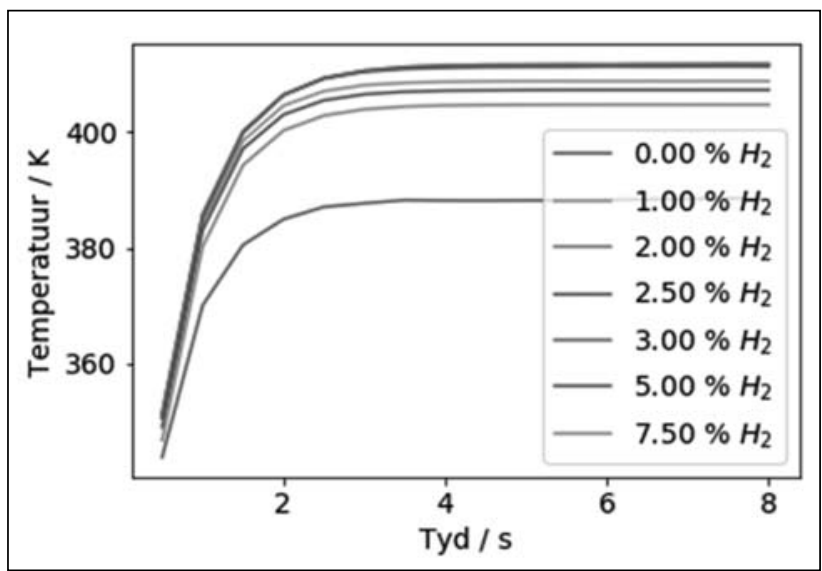

FIGUUR 5: Plasmabranderwandtemperatuur by die z-posisie waar dit piek teenoor tyd. 
Figuur 6 wys die temperatuurprofiel $1 \mathrm{~mm}$ weg van die binnewand oor die volle lengte van die brander vir verskillende konsentrasies van $\mathrm{H}_{2}$ in die skermgas by die finale tydstap. Die maksimum temperatuur naby die wand bo $2.0 \% \mathrm{H}_{2}$ is onder $5000 \mathrm{~K}$. Dit is die temperatuur waar argon begin om te ioniseer. Dit beteken dus dat daar geen plasmavorming by die wand plaasvind nie.

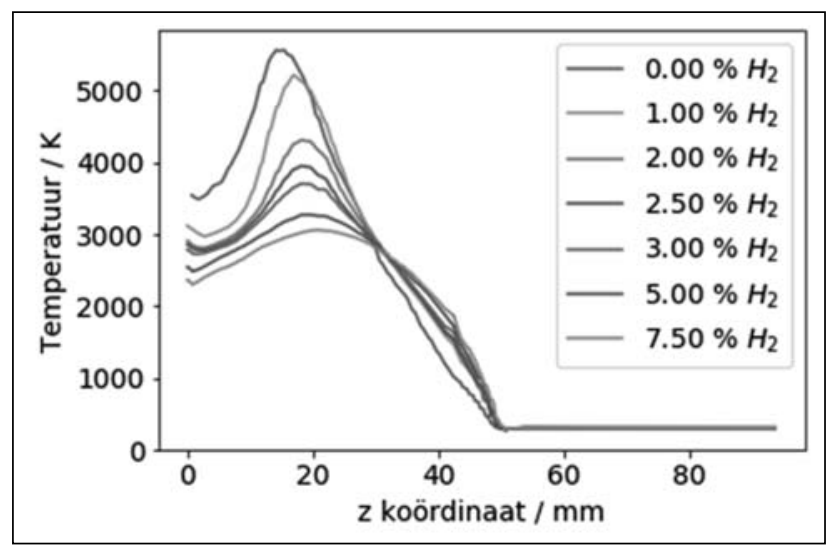

FIGUUR 6: Temperatuur $1 \mathrm{~mm}$ van die binnewand vir veskillende konsentrasies $\mathrm{H}_{2}$ in die skermgas.

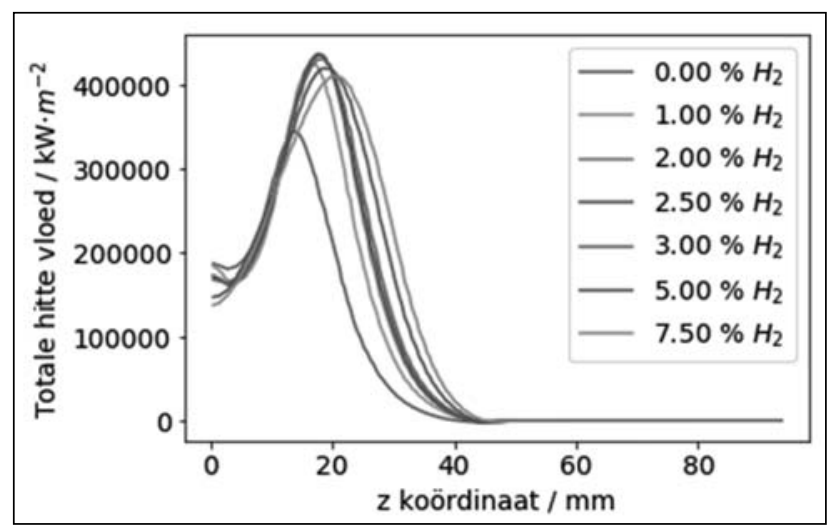

FIGUUR 7: Totale hittevloed oor die buitewand by verskillende konsentrasies $\mathrm{H}_{2}$ gas.
Figuur 7 wys die totale normaalhittevloed oor die buitewand vir verskillende konsentrasies van $\mathrm{H}_{2}$ gas. Dit is duidelik dat die $\mathrm{H}_{2}$ 'n groot invloed het tot by $2.0 \mathrm{~mol} \%$ en dat ' $n$ verdere verhoging in die $\mathrm{H}_{2}$ konsentrasie nie beduidend is nie.

Figuur 8 toon die stralingsverliese geïntegreer oor die hoogtevirdiesisteemas'nfunksievanwaterstofkonsentrasie in die skermgas.

Daar is 'n lokale minimum by $3 \% \mathrm{H}_{2}$ in die skermgas. Dit is ook bo die minimum hoeveelheid benodig om plasmavorming by die wand te voorkom.

Figuur 9 wys die temperatuurveld vir $0 \mathrm{~mol} \%, 3 \mathrm{~mol} \%$ en $7.5 \mathrm{~mol} \% \mathrm{H}_{2}$ en toon aan hoe die hittesone na links beweeg met meer waterstof in die skermgas. Figuur 10 dui ook op die beweging van die hittesone na links met 'n toename van $\mathrm{H}_{2}$ in die skermgas. Die maksimum temperatuur skuif bykans $4 \mathrm{~mm}$ links wanneer die $\mathrm{H}_{2}$ in die skermgas toeneem van $0 \%$ na $7.5 \%$.

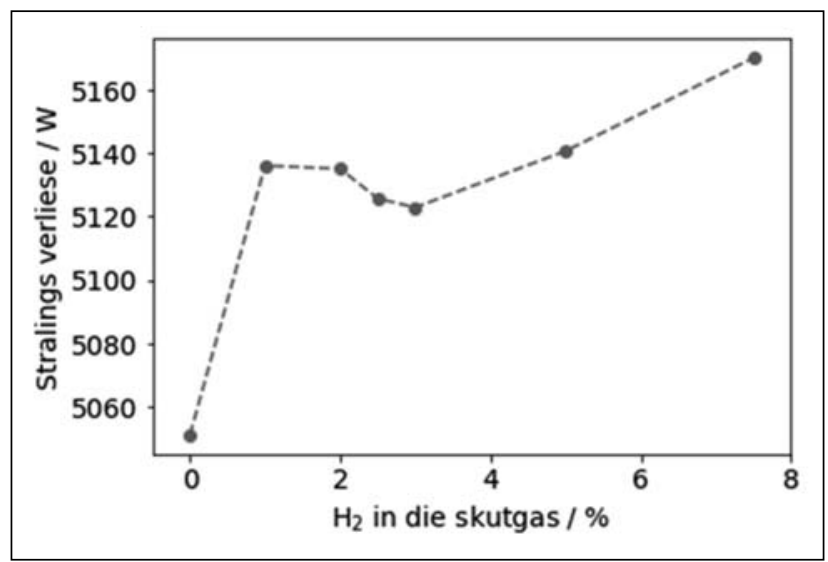

FIGUUR 8: Stralingsverliese met 'n lokale minimum by $3 \% \mathrm{H}_{2}$ in die skermgas
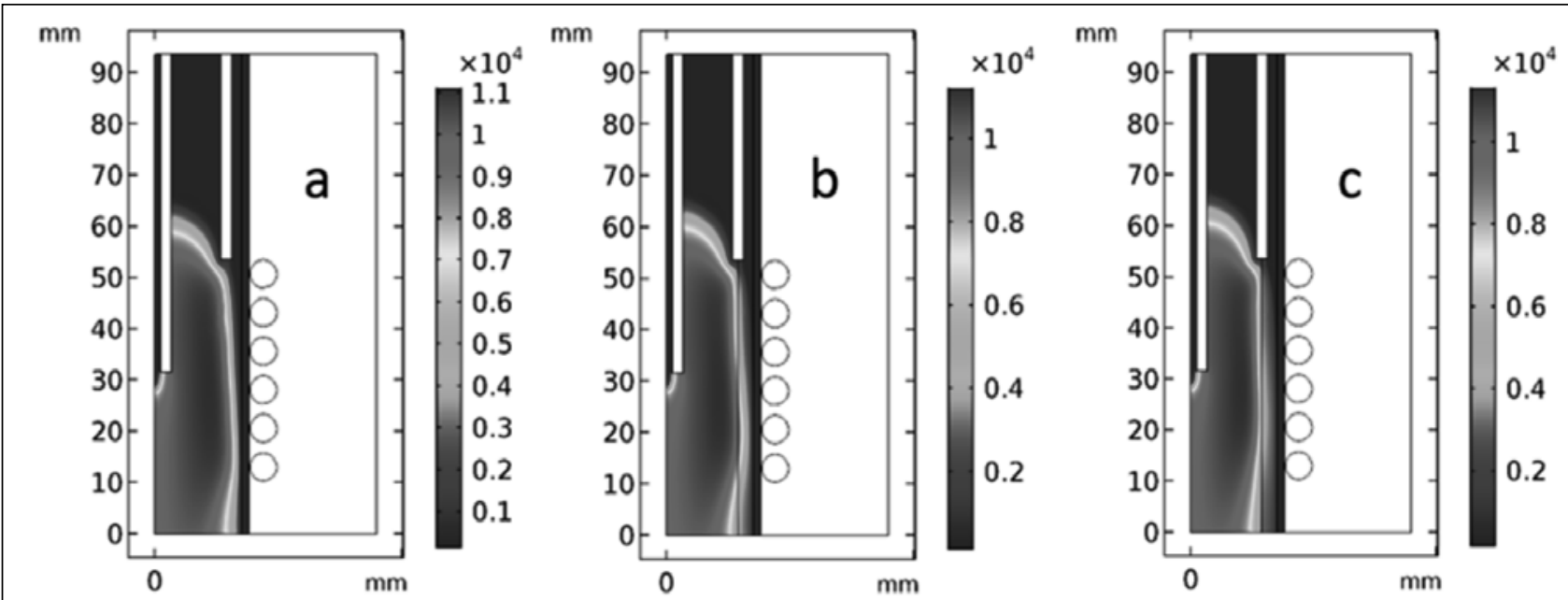

FIGUUR 9: Temperatuurkontoere met: a) $0 \mathrm{~mol} \%$, b) $3 \mathrm{~mol} \%$ en c) $7.5 \mathrm{~mol} \% \mathrm{H}_{2}$ in die skermgas. 


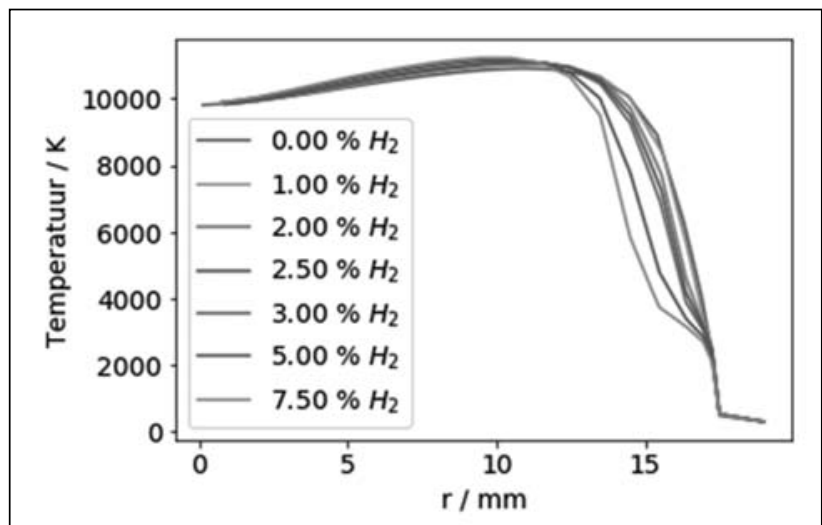

FIGUUR 10: Radiale temperatuurprofiel by die maksimum temperatuur.

Waterstof in die skermgas verminder duidelik die temperatuur op die binnewand en verminder daardeur hitteverliese deur die wand terwyl dit aanleiding gee tot 'n warmer plasma in die prosesseringssone, wat voordelig vir sferoïdiserings is. Die wand bereik 'n maksimum temperatuur van slegs $526 \mathrm{~K}$ met $3 \% \mathrm{H}_{2}$ in die skermgas. Hierdie temperatuur is laag genoeg om termiese skade op die binnewand te voorkom en steeds 'n minimale effek op die plasma en energiekostes te hê. Waterstof in die skermgas verbeter egter die hitte-oordrag na die wand en het 'n hoër temperatuur in die wand as gevolg van 'n kompeterende effek.

\section{Gevolgtrekking}

Die rekenaarmodel dui daarop dat die wand van plasmavorming beskerm kan word met 'n waterstof/ argon-skermgas met 'n minimum van $2 \% \mathrm{H}_{2}$. Waterstof veroorsaak ook 'n warmer plasma, maar te veel kan die plasma blus. Uit 'n ekonomiese oogpunt word so min as moontlik waterstof verkies. Daar is ' $n$ minimum in die stralingsverliese by $3 \% \mathrm{H}_{2}$ wat bo die minimum hoeveelheid is om plasmavorming te voorkom. Daarom is $3 \% \mathrm{H}_{2}$ gekies as die optimale bedryfspunt vir die IGP.

\section{Verwysings}

Aghaei M, Bogaerts A. 2016. Particle transport through an inductively coupled plasma torch: elemental droplet evaporation. Journal of Analytical Atomic Spectrometry 31, 631-641.

Ansys Fluent 2018 Ansys Fluent https://www.ansys.com/products/fluids/ansysfluent [16 July 2018].

Bogaerts A, Aghaei M. 2017. Inductively coupled plasma-mass spectrometry: insights through computer modeling. Journal of Analytical Atomic Spectrometry 32, 233-261.

Bolot $\mathrm{R}$, et al. 2007. Modeling of an inductively coupled plasma for the synthesis of nanoparticles. Journal of Thermal Spray Technology 16, 690-697.

Boulos MI. 1978. Heating of powders in the fire ball of an induction plasma. IEEE Transactions on Plasma Science 6, 93-106.

Boulos MI, Fauchais P, Pfender E. 1994. Thermal Plasmas: Fundamentals and Applications. Plenum Press, New York, pp. 388-447.

Colombo V, Ghedini E, Mostaghimi J. 2008. Three-dimensional modeling of an inductively coupled plasma torch for spectroscopic analysis. IEEE Transactions on Plasma Science 36, 1040-1041.

COMSOL Multiphysics 2018 COMSOL Multiphysics 5.3a https://www.comsol.com/ [16 July 2018].

Ikhlef $\mathrm{N}$, et al. 2012. Nonlinear compressible magnetohydrodynamic flows modeling of a process ICP torch. The European Physical Journal Applied modeling of a process
Physics 58, 10804-10813.

Mostaghimi J, Proulx P, Boulos MI. 1985. Computer modeling of the emission patterns for a spectrochemical ICP. Numerical Heat Transfer 8, 153-166.

Murr LE, et al. 2012. Fabrication of metal and alloy components by additive manufacturing: Examples of 3D materials science. Journal of Materials Research and Technology 1(1), 42-54.

Proulx P, Mostaghimi J, Boulos MI. 1985. Plasma-particle interaction effects in induction plasma modeling under dense loading conditions. International Journal of Heat and Mass Transfer 28, 1327-1336.

Proulx P, Mostaghimi J, Boulos MI. 1987. Heating of powders in an r.f. inductivelycoupled plasma under dense loading conditions. Plasma Chemistry and Plasma Processing 7, 29-52.

SY163 15 kW Induction Plasma System Original Operating Manual 2016 Tekna Plasma Systems Inc. Sherbrooke.

Tekna Spheroidization system Teksohero-15 system 2016 http://www.tekna.com/ landing-page/teksphero-15 [16 July 2018].

Yang $\mathrm{P}$, et al. 1989. Application of a two-dimensional model in the simulation of an analytical inductively coupled plasma discharge. Spectrochimica Acta, Part B 44 657-666. 